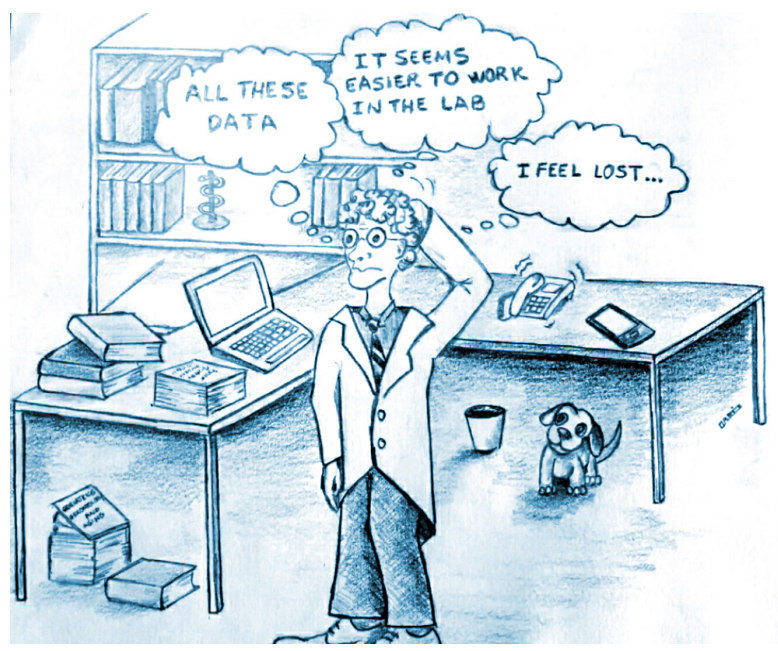

Cortesy of Cláudio Florido Rodrigues M.D.

\title{
INITIAL STEPS IN WRITING AND SUBMITTING A RESEARCH PAPER
}

\section{Passos iniciais na elaboração e submissão de um manuscrito}

\author{
Denise Pinheiro Falcão ${ }^{a}$, Anthony Terrence O'Brienb Rivadávio Fernandes Batista de Amorimº, \\ Heitor Morenob, Felipe Fregnib, Maria Regina Chalita ${ }^{a}$
}

BACKGROUND: This article is part of a special series designed to help authors in the process of scientific writing. OBJECTIVE: To address the steps that should precede the writing and submission of a research paper in order to optimize the process. METHOD: The authors discussed among them some strategies that should be adopted before properly starting the manuscript writing. RESULTS: Key strategies were organized into five thematic groups, namely: 1) How to prepare yourself for writing, 2) How to organize and prepare the writing tools, 3) How to elaborate a draft, 4) How to choose a journal, and 5) Who should be an author. CONCLUSION: Key strategies should be adopted before writing and submitting a research paper. Such strategies might improve the author's performance, optimize the time spent, and promote a high-quality communication writing, more pleasantly. KEYWORDS: scientific writing; manuscript; authorship; education; publications.

INTRODUÇÃO: Este artigo é parte de uma série especial que foi desenvolvida para auxiliar autores no processo da redação científica. OBJETIVO: Abordar as etapas que devem preceder a redação e a submissão de artigos científicos com o intuito de aprimorar o processo. MÉTODOS: Os autores discutiram entre si algumas estratégias que cada um costumava adotar antes de iniciar propriamente a redação de um manuscrito. RESULTADOS: Foram estabelecidas cinco etapas estratégicas relativas ao preparo prévio à redação de um manuscrito, a saber: 1) Como se preparar para a escrita, 2) Como organizar e preparar as ferramentas de escrita, 3) Como elaborar um esboço, 4) Como escolher um periódico e 5) Quem deve ser um autor. CONCLUSÃO: Deve-se considerar a adoção de estratégias-chave antes de se iniciar a redação e a submissão de um manuscrito. Tais estratégias podem melhorar o desempenho do autor, otimizar o tempo gasto e promover uma comunicação escrita de alta qualidade, de uma maneira mais prazerosa.

PALAVRAS-CHAVE: redação científica; manuscrito; autoria; educação; publicações.

aFaculdade de Medicina, Universidade de Brasília (UnB) - Brasília (DF), Brazil.

'Laboratory of Neuromodulation \& Center for Clinical Research Learning, Physics and Rehabilitation Department, Spaulding Rehabilitation Hospital, Harvard Medical School - Boston, USA. 


\section{INTRODUCTION}

All too familiar is the struggle that researchers face when writing a scientific paper. Often, they feel overwhelmed when challenged with the task of condensing years of research into a succinct and relevant text. Historically, renowned personalities from the scientific community also demonstrated such affliction: ${ }^{1,2}$ "A naturalist's life would be a happy one if he had only to observe and never to write" (Charles Darwin). In addition, William Osler stated: "There is no more difficult art to acquire than the art of observation, and for some men it is quite as difficult to record an observation in brief and plain language".

Nevertheless, scientific writing can, and should, be an enjoyable task. In order to help young researchers and clinicians, this text and subsequent series will present key points that can aid the process. They can help lay the groundwork for circulating scientific texts, while increasing reader's interest, comprehension and coverage. Habitually, novice researchers develop these skills after spending months or years on a research project, writing and submitting manuscripts. Experienced reviewers critically evaluate the manuscripts, and thus, authors have the opportunity to improve their writing abilities. A structured approach to writing indisputably reduces hastily formed ideas and burden on the researcher, while it accelerates the writing process.

Therefore, the aim of this article was to lessen the strain that researchers may experience when writing scientific articles. For this purpose, the authors discussed among them some strategies that each one usually adopted before properly starting the manuscript, in order to optimize the scientific writing process and to make it a rewarding task. Key strategies were organized into five thematic groups, namely:

- how to prepare yourself for writing;

- how to organize and prepare the writing tools;

- how to elaborate a draft;

- how to choose a journal;

- who should be an author.

It is important to mention that long before writing an article, an adequate methodological design, execution and analysis of the project would substantially influence its acceptance into a scientific journal. No attempts were made to include rules on writing structure or grammar.

\section{HOW TO PREPARE YOURSELF}

Writing tends to evoke anxiety that can result in a paralytic condition known as "writer's block". Doctor Edmund Bergler, a famous Austrian psychiatrist, created this term in 1947. Lack of inspiration, illness, depression, financial pressure, and a sense of failure can partially explain such condition. ${ }^{3}$ However, methodicalness and routinization are skills that must be refined by those who intend to be successful writers, regardless of whether writing a manuscript, theses or any other type of writing. Such abilities offer considerable advantages when compared to those who do not acquire commitment and let procrastination takes place, or simply decide to keep waiting for a moment of inspiration. ${ }^{4}$

Writing should be viewed as a pleasant and absorbing activity from start to end. Nonetheless, it is important to recognize the conditions and circumstances in which one feels most comfortable to write. Moreover, have consciousness about the importance of self-commitment and persistence and acquire some good work routine habits. Such abilities push ones towards goals and achievements.

\section{Self-awareness and time}

It is part of the process to identify the ideal time of the day for writing. The period whether morning, afternoon, evening, or night can dramatically influence the enjoyment, and productivity of writing.

In case someone is more productive at night, this period of the day should be booked to write, and the morning (possibly a less-yield period for this person) be used for "mechanical activities", as reviewing references and formatting tables. ${ }^{5}$

The time spent writing is also a critical aspect to consider. It should be taken into account the length of author's creative attention. What would be the optimal length of an effective writing session that author could maintain? For example, allocated blocks of at least two hours should be established prior to the beginning, in which other routine aspects of day-to-day are postponed until afterwards. ${ }^{6}$ This is more crucial than frustratingly putting together ideas on the spur whenever free time is available, or even spending much long in unproductive writing sessions.

Establishing periods of goal-oriented work interlaced with resting phases, 5-10-minute breaks, can help improve productivity. Setting focused, small, and clear objectives in these periods can help drive writing. For example, using two hours on Monday and Friday mornings, in which 50-minute writing goals are interlaced with 10-minute breaks to mentally and physically stretch can give flow to writing. However, it is important to decide whether length or frequency of writing sessions fits better to the author. ${ }^{5}$ Regardless the choice, make some notes of the final writing session thinking. This will avoid loss of important ideas between sessions and will help to recapture a linear reasoning for the next session start.

Therefore, before starting the writing phase of the research, organize your schedule to allow the writing compatible with work activities and attention to the family. 
Spatial awareness

Likewise, mental acuteness is also influenced by one's surroundings. Be aware to minimize the chances of interruption when writing. Aspects such as background sound, like white noise, cold or hot lighting, organization of the writing area, temperature, colors of the walls, environment objects, location, and transit of persons throughout it should be regarded. Furthermore, it should be considered the immediate availability of coffee, water, small healthy snacks and other primary needs to be attended, since they can modify the writing behavior.

The overarching goal is to feel comfortable, goal-oriented, and not stuck in one position mentally, temporally and physically, for too long.

\section{Drive}

Being able to hone in on one task is an acquired skill that requires persistence. This ties in nicely with Will Durant's 1926 interpretation of Aristotle's Nichomachean philosophy: "We are what we repeatedly do. Excellence, then, is not an act but a habit". ${ }^{7}$

Everyone should take steps to reduce interruptions when writing, regardless if easily distracted or not. Cell phones should be turned off, internet use reduced to a minimum, if not all together, and relevant reading material should be stored virtually or printed ahead of time. During the established resting periods, the researcher can answer calls and e-mails. No longer than five minutes should be spent answering phone calls or messages. Do not allow less important tasks to take precious time for manuscript writing.

Finally, setting less, and larger reasonable goals, as a deadline is equally important to finishing a manuscript. The deadline has to be prior to the official submission deadline to give enough time to distance oneself from the completed text, to allow reviewers to give feedback, and to have re-editing time and time for submission (Chart 1).

\section{PREPARING THE TOOLS}

All resources used to prepare and store the manuscript are considered writing tools. Thus, one should organize and prepare the computer, organize the articles to be cited, and manage the created files during the writing process and backup resources.

\section{Hardware and software}

The computer needs to be reliable and functional and fit the basic needs of the writer at the time of writing. For example, it should have a designated writing software, enough virtual memory to track edited changes, storage to save citations and multiple draft versions, statistical analysis and graph software if needed, an adequate antivirus, reference manager software, and a backup encrypted virtual drive, or if allowed in the institution, online storage or an external hard drive. The same pieces of software should be used across the board by coauthors to prevent conflicting software problems, for example, this can occur if different reference managers are used.

Regarding this last issue, it should be verified if the reference manager software coauthors would accept using it. There are several payed and free software options. Some institutions support authors for commercial versions, such as Bookends, Endnote, Lab Meeting, Papers, pdf Stack, ProCite, RefMan, Ref Works, and Sente, while others do not dispose a piece of reference manager software.

Free software such as 2collab, Biblioscape, Bookends, Citeulike, Citavi, Connotea,Jab Ref, Mendeley, Qiqqa, Refbase, WizFolio and Zotero can be helpful to optimize the workflow by all coauthors. Pre select three options to discuss the pros and cons with your pairs. However, before deciding for a specific software, verify its operational system and the minimal system requirements to have a good performance. Not all the reference managers are compatible with all the operating systems, thus this could help to narrow down the possible options.

Among free reference manager software, Mendeley has been gaining academic attention. It has a user-friend platform, allows filtering and selecting papers based on authors, tags, and keywords. It also provides resources to define your own tags and group articles by subject, and to select articles by author. The software allows making notes on the file, as well as to synchronize multiple computers, tablets and smartphones, as it copies all articles to a central database online.

The use of such resources can help save time by facilitating individual and group goals.

\section{Chart 1 Brief points on preparing to write}

\begin{tabular}{|l|}
\hline - Know your ideal writing place, such as the office in the \\
morning, when no one is around. \\
\hline - Separate at least two days for writing, e.g. Monday and Friday. \\
\hline - Remove distractors: internet, cellphone etc. \\
\hline - Set spaced goals during writing sessions. \\
\hline - Take small breaks in between to briefly attend to other \\
matters and stretch. \\
\hline - Have larger, but less, long-term goals, e.g. finish \\
methodology section by the following week. \\
- Drive/focus is a conscious act, until it becomes second \\
nature. Make constant efforts to maintain it. \\
\hline - Deadlines should be set a few weeks prior to submission \\
dates, for reviewing and editing by peers and self.
\end{tabular}




\section{Articles to be referenced}

The article reflects a long-term investment to science, a culmination of intellectual contribution honed through carefully crafted technique, revision, collaboration, mentorship, and commitment. Before writing or even collecting data, authors should have clearly established the primary and the co-primary objectives of the study, besides the secondary aims; all of which should be founded on a precisely formulated and warranted scientific hypothesis. ${ }^{8}$

Therefore, long before putting a "pen to paper", a compendium of previous scientific literature should have been mined, reviewed, and summarized. The important points in it should have been highlighted using notes that do not have to be too detailed and can be organized according to the author. One method is to use headers with the main idea combined with brief jottings in a separate electronic document or notepad. For example, the author can also put in parenthesis or in the margins comments such as "useful for elaborating introduction", "can potentially be used to compare with results", or even smaller annotations like "intro" or " methods". It is of up most importance to always keep these notes properly cited for future use, and in this sense, the previous section on citation manager coalesces. Another method is to summarize the key points in an Excel sheet. In the end, the method should enable writing by being accessible. ${ }^{9}$

Important aspects refer to the name of the articles files, and storage access to these texts and notes. The name of the file should facilitate a quick search. Thus, it should be adopted a single way of saving the files. For example, the file can be saved by using the title, authors' name and year: "Previous steps in writing and submitting a research paper_ Falcão_2016”. Regarding storage access, avoid solely having access through the internet, as it can deviate author's attention and interrupt the writing process.

\section{File management}

During the document elaboration, various versions will be produced. There will be an original draft, which over time will be edited into multiple versions; as coauthors contribute, there can be conflicts regarding copies and as such efficiency. In order to circumvent this problem, there are multiple cloud-based applications that can be used simultaneously, or at least the authors will be aware of when they can work on the document and who else is working on it. Develop in many of these programs is a track-changes option, which should always be used. Another critical step to follow is naming the version of the file when making major additions, or at least when editing, adding the date, like in: "Draft_writingsteps_version_12_13_2015". These versions should be backed up and safely stored in a separate folder, so authors do not get confused. Another useful tip is to always check the date of the last file before opening the document, and to compare with other versions if any doubts come up (Figure 1).

Having a backup of a properly labeled "last version" on a computer and on a webmail provider is recommended. Finally, schedules for reviewing the file among authors can be established to reduce the number of potential duplicates. For example, a range of dates can be blocked out to work on the document, after which the file will be passed on to the next reviewer, until all involved coauthors finalize the draft evaluation.

The time invested into these aspects will pay off in time gained for writing (Chart 2).

\section{HOW TO START ELABORATING A DRAFT}

It is important to understand that scientific writing is not a linear process, and frequently requires re-writing. To this end, getting down an idea can be more relevant than spending

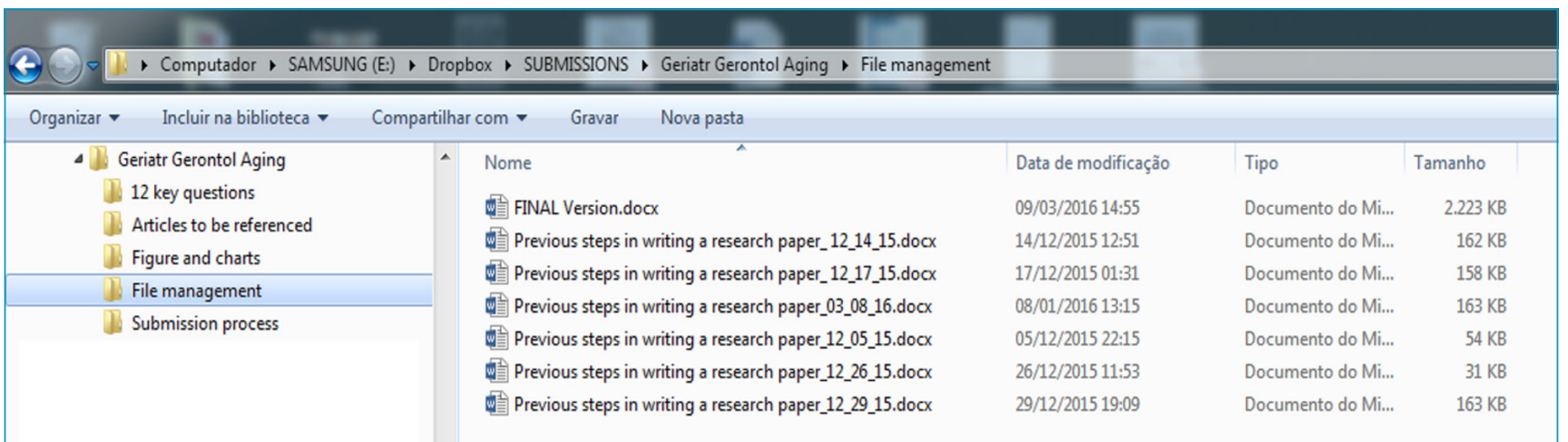

Figure 1 Alternate example of how to label and manage files (Windows 7 Home Premium@, 2009 - Microsoft) 
several minutes or hours to perfect a sentence, paragraph, or section. It is also necessary to know the type of article one is elaborating. Depending on whether the project is an original investigation, a review, a perspective or a comment will influence its structure.

Many times, it is not clear for the authors what are the main points to be mentioned, and sometimes, neither the research question. Hence, the text becomes lengthy and uninteresting for the reader. The writing process implies in transforming ideas into a written text. Writing the first draft is a great challenge once it requires the continual clarification and refining of reasoning.

Some doubts are frequent, such as "How should the matter be approached?" or "By where and how should the manuscript be started?". There are different ways to explore a subject, and the author has to choose one direction.

In this context, careful elaboration of the draft is an important step since it will help in organizing thoughts and will guide the manuscript writing. Furthermore, it is a mean for developing ideas in a clear, coherent, and succinct manner.

Clear writing allows the reader to capture the idea that, in fact, the authors have proposed to move on to readers. The text should not give rise to different interpretations. Coherence acts as a link between ideas, allowing the construction of a continuous and enjoyable way of reasoning. The text should be succinct, since the scientific language is quite different from the literary one and does not allow long, complex, and speculative phrases.

\section{Chart 2 Brief points on preparing the tools}

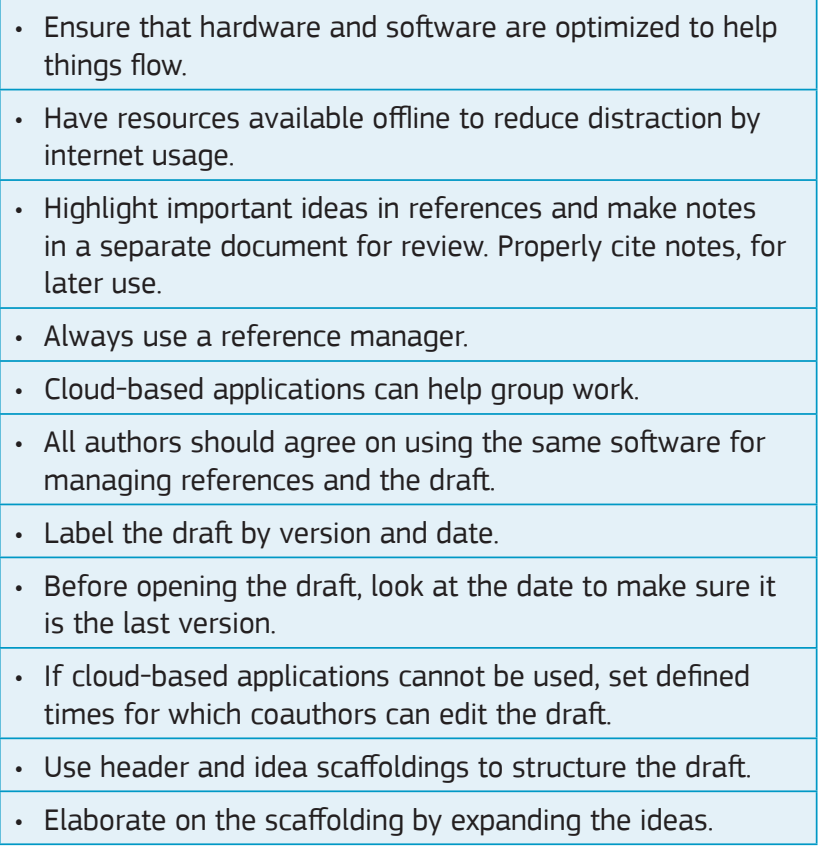

However, not rarely, the draft stage is often neglected, compromising the quality of the presentation of a well-conducted research. Be aware that the time spent at this stage is the time gained for the manuscript writing.

\section{The purpose of a draft}

A draft basically has four goals: delimiting the main points; organizing the ideas to be presented in a logical way to support a line of argument; helping establishing relations among ideas; defining the scope of a text, that is, what will be covered and what will not be approached in it.

\section{The main points}

The draft elaboration basely consists in answering 12 key questions. However, the answers must go through four stages. In the first one, the questions should be answered very succinctly, something like a brainstorm. In the second stage, the answers should be further explored, which means analyzing the main point of the issue without worrying about grammar or spelling. The next step is the improvement of answers. Sentences should be submitted to corrections of spelling and grammar. The fourth and final step is sending the draft to be reviewed by all coauthors by requesting them to verify whether the main points are present and whether the ideas are clear, coherent, and succinct. In this stage, coauthors should also complement the draft. All of them have to participate in the draft elaboration. Multiple authors cannot write a manuscript and one person has to take the lead, but it is essential that all coauthors read and complement a draft (Chart 3).

Chart 3 Brief points on the 12 key questions in elaborating the draft

\begin{tabular}{|l|}
\hline 1. What is the research question? \\
\hline 2. Why is it important? \\
\hline 3. How did you get this question? \\
\hline 4. What materials and methods were used to test the hypothesis? \\
\hline 5. List all figures and give titles for them. \\
\hline 6. What is the main result? \\
\hline 7. What are the interpretation of the findings? \\
\hline 8. What are the study limitations? \\
\hline 9. What are the positive differential aspects of the study? \\
\hline 10. What are the implications of the findings? \\
\hline 11. What is the usefulness of the findings? \\
\hline 12. What is the relevance of the study? \\
\hline
\end{tabular}




\section{HOW TO CHOOSE A JOURNAL}

The final process of writing is the dissemination of one's contribution to the scientific community. Therefore, selecting a journal ahead of time cannot only prove useful for knowing the target audience, but also for confirming the journal aims, and the content required by the journal for acceptance. In addition, knowing the publication permits the author to anticipate its impact ahead of time if accepted. Metrics such as the impact factor in the last five years; indexation at MEDLINE; if it is a specialty/ general and/or surgical/non-surgical; local/international publication can give a view of how one's article may permeate the field. ${ }^{10}$ The period between submission, acceptance and publication should also be considered in accordance to the groups' need.

These considerations provide a foundation for arming and selecting potential journals for publication. The authors should consider more than one option, in order to compare and contrast the best one. Three to five journals are adequate for this purpose. Always look at the information provided by the journal to authors as it not only orients the author, but leads to a reduction in time spent writing the draft.

When searching for the journals, the list of references used for the construction of other sections can be useful. Furthermore, coauthors, mentors, and specialists such as librarians, or faculty can be of great service. Online databases can similarly guide the decision. Finally, reading articles from highly regarded scientific papers in your research area, including papers in the journal to which you plan to submit your current work, is essential to appreciate the journals requirements (Chart 4$).{ }^{11}$

\section{WHO SHOULD BE AN AUTHOR}

An author is anyone who has made an intellectual and scientific contribution to the article. Manual work, while being part of the scientific process, does not guarantee authorship, and the same is considered with attaining a grant and or

\section{Chart 4 Brief points for choosing a journal}

- When choosing a journal, reflect on the audience that
will be reading your draft, the impact metrics, the aims
of the journal, the characteristics of the journal and its
requirements. Also, consider the needs of the authors.
- Use resources, like colleagues, references, librarians,
mentors, etc.
- Choose three to five journals; review at least one article
from each.
- Look at the author's instructions.

through seniority. It also reflects an agreement on accountability. The International Committee of Medical Journal Editors (ICMJE) has four criteria to define 'who should be an author', which serve to help decide on authorship. They are:

- substantial contributions to the work conception or design; or the acquisition, analysis, or interpretation of data for the work;

- drafting the work or revising it critically for important intellectual content;

- final approval of the version to be published;

- agreement to be accountable for all aspects of the work in ensuring that questions related to the accuracy or integrity of any part of the work are appropriately investigated and resolved.

There should be a lead author in charge of guiding and constructing the overall text, which is not absolutely necessary though as on occasion equally contributing authorship can occur. In the end, it depends on the project and the way in which the group works with each other. However, there should also be an agreement about the authorship in the manuscript. Scientific writing is a dynamic process and, under certain circumstances, the order can change if all authors agree on it.

\section{FINAL REMARKS}

Writing is an important mean by which science is communicated. In order to truly improve the process, researchers should engage in the activity. Before starting the writing and submitting a manuscript, authors should be aware of themselves, of the environment, tools, roles and purposes of the paper. Such issues will help driving the content and significance of the article. Not only it has to be concise, coherent and clear. The manuscript has also to be important, interesting, engaging and seductive. Thus, it should be considered adopting key strategies before starting writing a manuscript. Such strategies may improve the author's performance, optimize the time spent and promote a high-quality communication writing, in a more pleasant way.

\section{ACKNOWLEDGEMENTS}

Denise Pinheiro Falcão thanks the Committee for the Development of Higher Education Personnel - Capes (Coordenação de Aperfeiçoamento de Pessoal de Nivel SuperiorBrazil) for the scholarship received to develop this work. The authors are grateful to Paulo Vitor Fernandes Braz for his suggestions to this text. 


\section{REFERENCES}

1. Horton R. The rhetoric of research. BMJ. 1995;310(6985):985-7.

2. Oslwer W. On the educational value of the medical society. Bost Med Surg J. 1903;148(11):275-9.

3. Castillo M. Writer's block. Am J Neuroradiology. 2014;35(6):1043-4.

4. Boice R. Professors as writers: a self-help guide to productive writing. Stillwater, OK: New Forums Press; 1990. 80p.

5. Zerubavel E. The clockwork muse: a practical guide to writing theses, dissertations, and books. Cambridge, Mass: Harvard University Press; 1999.

6. Kotz D, Cals JW. Effective writing and publishing scientific papers--part I: how to get started. J Clin Epidemiol. 2013;66(4):397.
7. Will D. Ethics and the nature of happiness. In: Story of philosophy. New York: Simon \& Schuster, Inc.; 1928. p. 96-102.

8. Provenzale JM. Ten principles to improve the likelihood of publication of a scientific manuscript. Am J Roentgenol. 2007;188(5):1179-82.

9. Veness M. Strategies to successfully publish your first manuscript. J Med Imaging Radiat Oncol. 2010;54(4):395-400.

10. Chipperfield L, Citrome L, Clark J, David FS, Enck R, Evangelista M, et al. Authors' Submission Toolkit: a practical guide to getting your research published. Curr Med Res Opin. 2010;26(8):1967-82.

11. Day RA, Gastel B. How to write and publish a scientific paper. 6 ed. Westport, Connecticut, London: Greenwood Press; 2006. 